\title{
RESISTÊNCIAS E REJEIÇÕES NAS VIVÊNCIAS DE PESSOAS TRANS NO CANDOMBLÉ DA BAHIA
}

\section{Resumo}

Neste artigo, analisam-se as experiências de três pessoas trans em terreiros de Candomblé localizados na cidade de Salvador, Bahia, Brasil. Através de entrevistas em profundidade, elas relataram como as suas identidades de gênero não foram respeitadas (no tocante a interdições de vestuário, nas relações interpessoais e na organização do trabalho ritual) e quais estratégias elas desenvolveram para continuar praticando a religião afro-brasileira e terem as suas identidades respeitadas.

Palavras-chave: Candomblé, transexualidades, gênero, teoria queer.

\section{Abstract \\ Resistances and rejections in the experiences of transsexual people in Candomblé of Bahia \\ The article analyzes the experiences of three trans persons in Candomblés terreiros in the city of Salvador, Bahia, Brazil. Through in-depth interviews, these people report on how their gender identities were not respected (interdictions on clothing, interpersonal relations and the organization of ritual work) and what strategies they developed to continue prac- ticing the Afro-Brazilian religion and have their identities respected.}

Keywords: Candomblé, transsexualities, gender, queer theory.

\section{Resumen \\ Resistencias y rechazos en las experiencias de personas trans en el Candomblé de} Bahía

En el artículo, se analizan las experiencias de tres personas trans en terreiros de Candomblé situados en la ciudad de Salvador, Bahía, Brasil. Desde entrevistas en profundidad, ellas relataron cómo sus identidades de género no fueron respetadas (en cuanto a prohibiciones de ropa, en las relaciones interpersonales y en la organización del trabajo ritual) y qué estrategias desarrollaron para seguir practicando la religión afrobrasileña y tener sus identidades respetadas.

Palabras clave: Candomblé, transexualidades, género, teoría queer.

* Coordenador Executivo do Grupo Homossexual da Periferia - GHP. Bacharel Interdisciplinar em Humanidades IHAC/UFBA, Mestrando no Programa de Pós-Graduação em Estudos Interdisciplinares sobre Mulheres, Gênero e Feminismo - PPGNEIM/FFCH/UFBA.

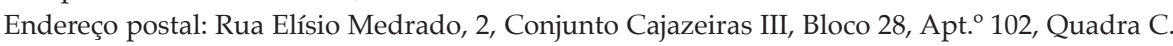
Águas Claras, Salvador, Bahia, Brasil. CEP: 41.311-296.

Correio eletrónico: diasghp@gmail.com

** Professor Associado I IHAC/UFBA.

Endereço postal: Rua Barão de Geremoabo, s/n, Ondina. Pavilhão de Aulas V, sala 307, Salvador, Bahia, Brasil. CEP: 40.170-155.

Correio eletrónico: leandro.colling@gmail.com 


\section{Introdução}

Este artigo é fruto de uma pesquisa que analisou as trajetórias de três pessoas, que se identificam como transexuais, ${ }^{1}$ em terreiros de Candomblé situados em comunidades periféricas na região metropolitana de Salvador, Bahia, Brasil. O trabalho teve o propósito de analisar, em diálogo com a perspectiva das pessoas trans, como as comunidades-terreiro lidam com as identidades de gênero não cisgêneros. A motivação desta investigação surgiu diante da observação dos autores deste trabalho, que frequentam terreiros em Salvador, acerca da invisibilização de transexuais e travestis nesses espaços. É importante pensar como essa religião afro-brasileira constrói discursividades que empoderam uma parte de seus adeptos, ao passo que torna invisível outros corpos, no caso deste estudo, especificamente, sujeitos que destoam das normas de gênero atribuídas social, cultural e historicamente.

Descrever exaustivamente o Candomblé e a sua história não é a finalidade deste texto. O Candomblé, baseado na crença na ancestralidade africana, diviniza forças da natureza e busca reconectar os seus adeptos às suas origens ancestrais. Trazido ao Brasil pelas pessoas negras escravizadas, se expandiu em parte do território brasileiro, se reconfigurou e é constituído por uma diversidade de cultos, assim como ocorre no continente africano, onde é realizado em regiões específicas, em geral, a partir de clãs, como afirma Roger Bastide (2001, 78).

Iremos evidenciar que essa religião afro-brasileira, embora se anuncie como acolhedora de todas as pessoas, possui restrições a certas identidades. Como sugere Vuola $(2015,43)$, «não se pode negar o sexismo das religiões» e no Candomblé não seria diferente. Mas como se manifesta a transfobia nessas comunidades religiosas? Para responder essa questão, entrevistámos em profundidade três pessoas trans. No curso das entrevistas, utilizámos o método das «histórias de vida», que consiste em um modelo no qual as pessoas colaboradoras passam a ser vistas enquanto sujeitas produtoras de suas realidades, com o objetivo de atribuir sentidos às suas vivências (Laville e Dionne 1999, 158). Na tentativa de promover ainda mais a autonomia das pessoas interlocutoras deste estudo, utilizámos as «produções narrativas» (Goikoetxea e Fernández 2014, 97), que promovem a interferência das pessoas entrevistadas no processo criativo da pesquisa. As entrevistas se deram em dois momentos distintos.

Em relação a nossa posição, enquanto pesquisadores, enfatizamos a atuação política que nos aproxima das pessoas interlocutoras desta pesquisa. Elas não se caracterizam como «meros objetos de pesquisa», mas produtoras de conhecimento situado e engajado a partir de suas vivências. E as nossas vivências de terreiro são,

No início das entrevistas, as três pessoas se identificaram como transexuais. No entanto, ao longo das conversas, elas também utilizavam a categoria trans para se identificar. Por isso, ora utilizaremos a categoria transexual, oriunda do saber médico, ora a categoria êmica «trans», que é resultado de uma construção política do movimento transfeminista. 
em boa medida, alguns dos fatores que nos aproximam. Para além da nossa condição de parceiros do movimento transfeminista, trans*aliados, somos também iniciados $^{2}$ no Candomblé, o que nos torna sujeitos implicados, diretamente, com as nossas interlocutoras.

A bibliografia acionada sobre a interface entre as religiosidades e as identidades trans e travestis (Bomfim 2009; Ribeiro 2009; Jesus 2012; Santos 2013; Romba 2015) ainda é muito pequena e pouco difundida. Contudo, dialoga, de maneira intensa, com a perspectiva das dissidências sexuais e de gênero, e suas autorias também podem ser consideradas como mais vozes trans ${ }^{*}$ aliadas. Entretanto, algumas questões devem ser pensadas para lançar novas problematizações sobre o lugar que devem ocupar as identidades transexuais e travestis nos espaços religiosos do Candomblé.

Sugerimos que as pessoas adeptas das religiões de matriz africana e as pessoas trans devem pensar sobre quais são as possibilidades de as transexualidades existirem nas comunidades-terreiro. O Candomblé, sendo uma das religiões de matriz africana, tem uma organização social e política própria, um contexto específico e, como não poderia ser diferente, também sofre os impactos das normas de gênero e sexualidade que vigoram na sociedade.

As religiões, em geral, têm negado às pessoas transexuais e travestis o direito de existir nas comunidades religiosas. Os espaços religiosos, que deveriam acolher indistintamente as pessoas que os procuram para um bem-estar espiritual, têm afastado determinadas pessoas do convívio e da afetividade religiosa. Em algumas igrejas católicas e evangélicas, no espiritismo e em algumas outras denominações religiosas cristãs, existe uma pseudoaceitação das pessoas LGBT, desde que elas tenham posturas e comportamentos aceitáveis para a convivência junto às suas comunidades religiosas. Essas «posturas», em geral, significam uma adesão às normas sociais de gênero e sexualidade, o que doravante denominamos, a partir de Viviane Vergueiro (2015), de cis-heteronormatividade. ${ }^{3} \mathrm{O}$ problema se agrava ainda mais em relação às identidades transexuais e travestis, em geral porque as suas próprias histórias, estigmas socioculturalmente construídos, existências e seus corpos já contestam e evidenciam pressupostos heteronormativos (Colling e Nogueira 2014) e cisgêneros (Vergueiro 2015).

Como enfatiza Bonfim $(2009,104)$, as travestis saem dos cultos antes que eles sejam finalizados por medo de represálias pela sua presença no espaço religioso das igrejas, o que talvez não ocorra em uma casa de Candomblé. Entretanto, os

Uma pessoa ingressa oficialmente no Candomblé após passar por um rito iniciático que varia muito entre as diversas casas e nações e a depender do orixá e do cargo ou posição que ela terá naquela comunidade-terreiro.

3 Viviane Vergueiro $(2015,57)$ sugeriu a junção entre os conceitos de heteronormatividade e cisgeneridade. Enquanto a heteronorma exige que todas as pessoas se enquadrem em um modo de vida heterossexual, a cisgeneridade exige que todas as pessoas se identifiquem com o gênero atribuído em seu nascimento. 
lugares que as mulheres trans precisam ocupar nos terreiros quase sempre estão ligados ao universo masculino. Um dos autores deste artigo presenciou, em vários momentos, em um terreiro tradicional de Salvador, algumas meninas trans e travestis serem ridicularizadas na arquibancada dos homens, embora a atual dirigente da casa, no documentário Cidade das Mulheres (2005), afirme que o terreiro acolhe todas as pessoas sem preconceitos.

Nos terreiros de Candomblé, muito embora as «suas portas» estejam sempre abertas para todas as pessoas, algumas restrições são mantidas em favor da manutenção da tradição religiosa. As pessoas que dirigem as casas de Candomblé, em geral, conduzem seus terreiros à luz dos ensinamentos das pessoas mais velhas e, justo por isso, temas como a transexualidade ainda não se tornaram caros para essas comunidades. O que há, nos parece, são acordos de aceitação nos moldes de outras expressões religiosas: aceitar desde que as pessoas se adequem às normas de gênero e sexualidade vigentes nas comunidades-terreiro, que são aquelas pautadas pela perspectiva heteronormativa e cisgênero. Nos terreiros de Candomblé existem funções específicas para homens e mulheres, identidades que quase sempre são pensadas dentro de uma perspectiva cisgênero. Mas as entrevistas que realizámos com pessoas trans também revelam que homens e mulheres trans resistem nessas comunidades religiosas.

\section{Aproximação com as pessoas participantes da pesquisa}

As interlocutoras deste trabalho se autodeclararam pessoas transexuais, negras e oriundas de comunidades periféricas de Salvador. Luana é esteticista, 37 anos, nascida em Cuiabá, Mato Grosso, filha de Oxum, ${ }^{4}$ foi iniciada no Ile Ase Ya Omin Lonan, uma casa filiada à Casa Branca, um tradicional terreiro de Candomblé da Bahia. A sua aproximação com a religiosidade se deu desde cedo, quando ela frequentava centros de Umbanda, nos quais desenvolveu a sua mediunidade, o que a levou ao rito iniciático no Candomblé.

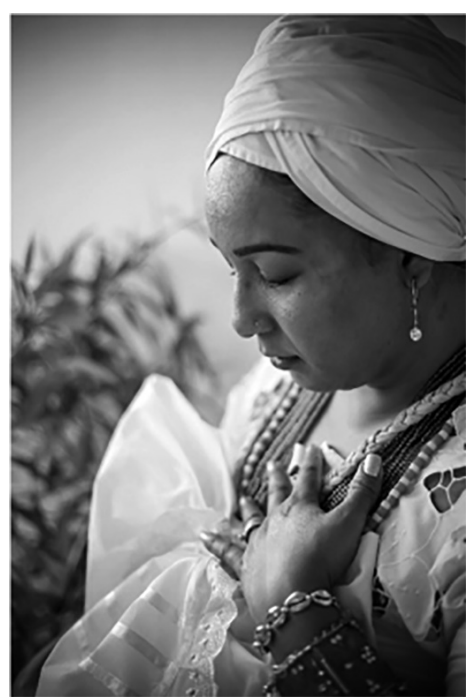

Imagem 1. Luana e o amor pelo sagrado. Foto: Andrea Magnoni

O Candomblé possui diversas divindades, chamadas de orixás nos terreiros da nação ketu e nkisis (ou inquices) na nação angola. Essas nações correspondem aos territórios africanos de onde vieram essas práticas religiosas. A nação ketu corresponderia a Nigéria e a nação angola ao Congo e Angola. Outra nação do Candomblé é o jeje, que cultua voduns que vieram do reino de Daomé, onde hoje se situa o Benim. 
Mauro é artesão, 34 anos, filho de Ossain, foi iniciado no Ile Ase Filandereir. Seu primeiro contato com a religião foi traumático porque ele era considerado como mulher no terreiro e já se percebia como um homem trans. Contudo, a convivência diária com as pessoas do terreiro fez com que ele passasse a se sentir parte daquela comunidade. Ele acredita que ocorreu um direcionamento dado pelo Orixá para sua aproximação com o seu terreiro.

Alana é ativista LGBT, luta contra a epidemia de HIV/AIDS e é educadora social. Tem 35 anos, é filha de Dandalunda, ${ }^{5}$ e foi iniciada no Terreiro Azê de Obaluae. Atualmente, ela é Nengua Nkisi (mãe de santo) em seu próprio terreiro, o Unzo de Ungunzo Kissimbe Amazi, localizado na região do Calabar, um bairro popular localizado na região central de Salvador. Também chegou ao Candomblé ainda criança, já que sua mãe foi

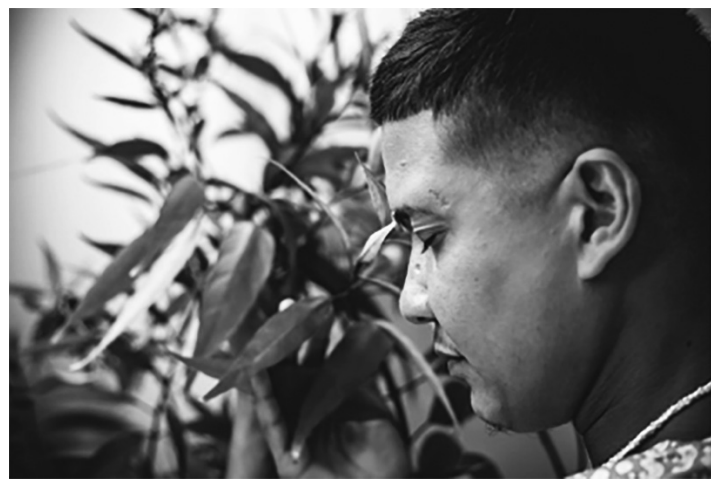

Imagem 2. Mauro é filho de Ossain, divindade das folhas. Foto: Andrea Magnoni

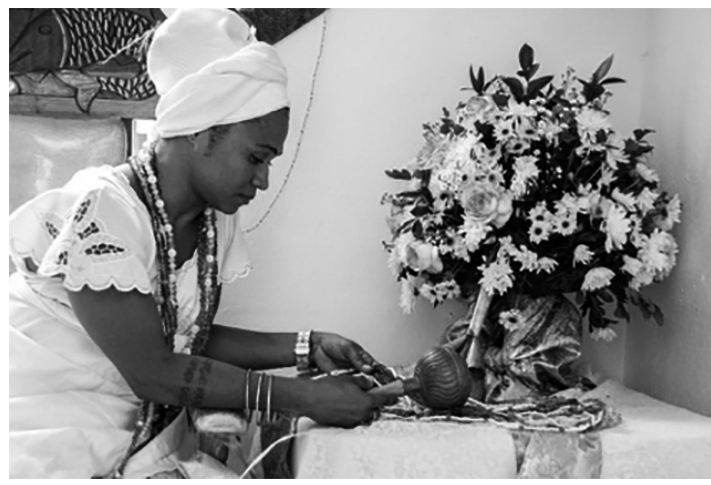

Imagem 3. Alana é ativista LGBT e filha de Dandalunda. Foto: Zazo Guerra iniciada na religião, embora não mais participe das liturgias do Candomblé. Alana tinha muitos problemas de saúde e disse que esse foi um dos fatores que a levou a procurar o terreiro de Pai Everaldo.

As vivências dessas três pessoas trans nas suas comunidades-terreiros foram bastante tensas desde a sua aproximação aos ritos iniciáticos e no decorrer de suas vidas nas casas de Candomblé. Até se constituir como uma líder religiosa - e ser respeitada como tal -, Alana passou por diversas situações que a levaram a afastamentos sistemáticos de sua primeira casa de Axé. Ao contrário de Mauro e Luana, que se afastaram de modo definitivo de suas raízes religiosas, Alana trilhou a sua

Divindade (Nkisis) da nação angola. 
vivência religiosa perseguindo o seu objetivo de galgar o posto de Nengua Nkisi. Contudo, vivenciou momentos de indecisão diante dos risos sarcásticos direcionados para ela.

O amor de Luana por suas divindades não fez com que ela esquecesse os processos de exotificação que foi obrigada a suportar durante o curto período em que esteve vinculada à sua casa raiz. Embora mantivesse certa regularidade e frequência na sua comunidade-religiosa, ela não se sentia pertencente àquele espaço em razão do sofrimento que enfrentava a cada vez que precisava se transfigurar em uma pessoa que não dialogava com a sua identidade de gênero.

Mauro constitui uma incógnita para alguns membros de sua comunidade religiosa. Embora houvesse um acordo de respeito à sua identidade trans, entre os adeptos daquela comunidade e seu líder religioso, várias questões de ordem pessoal impediam que tal acordo fosse efetivado. As agressões reportadas variavam do simples xingamento até à deslegitimação de sua identidade de gênero.

Essas três pessoas possuem muito de seus Orixás/Nkisis. A docilidade aliada à astúcia de Oxum/Dandalunda é comum entre Luana e Alana, bem como é possível reconhecer em Mauro a exuberância e o potencial criativo de Ossain. É também notável, na condução de suas buscas, os caminhos trilhados por Exu, além da presença de sua desenvoltura para se proteger nos momentos necessários e externar alegrias nos momentos mais adversos.

Traçaremos, nas próximas seções, algumas das principais problemáticas enfrentadas por essas pessoas nas suas comunidades-terreiro, com o objetivo de buscar alternativas de desconstrução das normas de gênero que ainda existem nas religiões de matriz africana. Desse modo, como pensar em uma aceitação indistinta dessas pessoas nas casas de culto, uma vez que muitas delas não respeitam as identidades de gênero de seus filhos e filhas?

\section{Vivências e interdições}

Mauro relatou várias formas de falta de respeito e discriminação para com ele no terreiro onde foi iniciado e enfatizou que as agressões verbais eram comuns no cotidiano. Sobre isso, ele entende:

que os pais de santo heteronormativos e as mães de santo são mais difíceis de aceitar. [...] A questão não é a tolerância, é o respeito, foi o que eu falei para o meu vizinho, eu não quero que vocês me tolerem, eu quero que vocês me respeitem. (Mauro, entrevistado em 7 de abril de 2016)

A falta de informação das comunidades religiosas é um fator preponderante para a não aceitação de identidades trans. Como afirma Judith Butler $(2008,38)$, o que não segue a lógica coerente entre «sexo-gênero-prática sexual-desejo» será 
visto e tratado como ininteligível ou ainda abjeto. Assim, a postura dos sujeitos, diante de situações não habituais à sua realidade, é fruto do desconhecimento sobre as outras possibilidades de vivências.

Mauro relata ainda que sofreu com a distância de sua família «biológica» e considera que sua família de $A x e ́$, em alguma medida, também reproduziu problemáticas vivenciadas no seio de sua família «original». O que é mais significativo desses relatos é a solicitação de um respeito independentemente de sua identidade de gênero ou orientação sexual. Viviane Vergueiro demonstra como a família pode ser um vetor de silenciamento das identidades trans e travestis, além de potencializar sentimentos de culpa por promover lugares subalternizados a corpos que destoam da ordem hegemônica (Vergueiro 2014, 176).

É notória a ausência de pessoas trans e travestis em muitos terreiros que têm como cerne de orientação a tradição. Luana foi iniciada em uma casa filiada ao Candomblé do Engenho Velho, a Casa Branca, uma das casas mais tradicionais da Bahia. Mesmo depois de uma relação pautada na verdade (e até na sua exposição pessoal ao dirigente), ela não foi reconhecida pela sua identidade de gênero e, em especial, pelo seu nome social, o que causou o sentimento de desvinculação e certa antipatia àquele espaço religioso. $\mathrm{O}$ que ela diz demonstra, dentre outras questões, o despreparo das pessoas dirigentes para lidar com temas como a transexualidade. Alana, por sua vez, do lugar de militante política, aponta:

A transfobia está aí, a homofobia está aí. Está sendo trazida para dentro dos terreiros de Candomblé. E isso é preocupante. Da homofobia se gera a violência, agressão e até o assassinato. Imagine? Diz que teve, em São Paulo, uma transexual Ialorixá que foi assassinada. Em Recife teve uma outra que também foi assassinada. Imagine se isso chega na Bahia? São dados preocupantes que a sociedade tem que se alertar para esse tipo de coisa. Principalmente, a sociedade dos terreiros que são massacrados o tempo todo pelo cristianismo, pelos evangélicos, pela sociedade hétero, pela sociedade cristã. E para você vê que o povo de Axé é tão desunido que existem 17 cadeiras na bancada e em nenhuma dessas 17 cadeiras existe um Babalorixá, uma Ialorixá, uma Makota, um Cambando, um Pejigan. ${ }^{6}$ Mas existem 17 evangélicos sentados e assumindo essas cadeiras. (Alana, entrevistada em 1 de fevereiro de 2017)

O facto de termos líderes religiosas/os LGBT e sensíveis às causas trans e travestis não impede que condutas cis-heteronormativas sejam percebidas nas relações das comunidades-terreiro. São processos violentos de negação de identidades que foram conquistadas com muita luta por reconhecimento e respeito. Luana e Alana têm uma história com a religiosidade afro-brasileira desde sua tenra

Alana evoca aqui alguns dos cargos existentes dentro dos terreiros. Esses são títulos honoríficos daquelas/es que cuidam dos Orixás e de seus locais de culto. Babalorixás e Yalorixás são os dirigentes das casas de nação Ketu. 
idade e o sentimento de pertencimento já se desenhava quando suas famílias possibilitavam o acesso ao mundo dos Orixás/Nkisis. Mauro, por sua vez, conheceu o Candomblé em sua fase adulta, o que lhe permitiu determinadas escolhas, ter a oportunidade de reivindicar uma identidade de gênero distinta e assumir uma personagem (por ter trajado vestes lidas como femininas em seu rito de iniciação).

\section{Vestuário religioso e os corpos trans}

Uma problemática comum a muitas pessoas trans e travestis nos espaços religiosos do Candomblé é a questão de vestuário, sobretudo para mulheres. Os/as dirigentes tendem a negar que elas usem roupas tidas como do gênero feminino porque entendem que elas são, na verdade, homens, uma vez que possuem pênis. $\mathrm{Na}$ visão das mulheres trans, ao menos as que foram entrevistadas neste estudo, o facto de elas não serem autorizadas a usar roupas tidas como compatíveis com a sua identidade feminina se constitui em uma relação abusiva de poder reproduzida pelas pessoas que dirigem as casas. Isso mostra como a relação hierárquica instituída espiritualmente nos terreiros de Candomblé pode se tornar abusiva quando o controle acaba por negar a existência das outras pessoas.

Enquanto para Luana ocorreu um choque de realidade quando ela foi obrigada a se vestir como uma pessoa que ela não é, Mauro experimentou uma relação de cordialidade no momento de sua iniciação. Ele relatou que, na sua iniciação, vestiu roupas tidas como femininas, mas que isso não foi um problema, pois assegurou, naquele momento, uma nova vivência na sua comunidade e com a sua espiritualidade. Ele interpretou essa experiência como mais um dos diversos trânsitos pelos quais passou em sua vida.

Luana, oriunda de uma casa filiada ao terreiro da Casa Branca, que tem uma arraigada tradição matrilinear, expôs as suas mais íntimas questões ao dirigente que a acolheu como filha, mas viu a sua identidade de gênero ser vilipendiada, $\mathrm{o}$ que a tornou retraída em relação ao convívio na sua casa de origem. Atribuímos o desrespeito à identidade de gênero de Luana ao facto de sua casa matriz cultivar valores tradicionais, que perseguem um ideal de "pureza» no Candomblé que, como já apontou Beatriz Gois (Dantas 1988, 148), «não faz sentido», uma vez que os traços de africanidade da religião afro-brasileira são distintos de sua concepção africana, para além de o nosso Candomblé ser, primordial e genuinamente, brasileiro.

Por sua vez, Mauro não se prendeu ao vestuário, uma vez que entrou em acordo com a comunidade religiosa, de modo que fosse sempre reconhecido e respeitado como um homem trans, mesmo diante do modo como foi iniciado naquela comunidade (usando roupas tidas como próprias da identidade feminina). Sobre os seus modos de vestir e sentir a comunidade, ele afirmou: «eu não sofro mais. Eu 
nunca sofri dentro do Ilê Axé, não. A única vez foi no rito de iniciação, por uma opção minha. Não foi uma opção nem do meu pai de santo» (Mauro, entrevistado em 7 de abril de 2016).

Embora o vestuário não seja um problema para Mauro, outras formas de violência apareceram e, em boa medida, o caminho utilizado por ele, em vários momentos, foi o de se afastar do terreiro. As relações entre ele e alguns irmãos de Axé tornaram-se tensas em meios a insultos e posturas arredias, xingamentos e deslegitimação da sua identidade trans. Isso o levou ao afastamento definitivo da casa onde ele foi iniciado. Luana, por sua vez, vivenciou o primeiro ano de iniciação com a sua identidade de gênero negada e por isso foi à procura de um espaço religioso que a respeitasse. Ela encontrou apoio indistinto em uma nova comunidade religiosa que compreende as suas especificidades e respeita a sua identidade.

Por causa dessas experiências, entendemos que as identidades transexuais e travestis constituem um novo lugar de resistência na religião afro-brasileira da atualidade. Dizemos isso pensando na resistência registrada no início do culto em terras brasileiras, quando as pessoas negras encontraram no sincretismo religioso o modo de continuar a reverenciar os/as deuses/as africanos/as ou, ainda, quando a polícia impedia ou controlava os cultos e rituais dos terreiros, dentre outros tantos exemplos. ${ }^{7}$ Para Luana, o despreparo de algumas autoridades religiosas ao lidar com a transexualidade é um facto e, como ela afirmou, existe uma política de exclusão nas comunidades-terreiro que está camuflada na teia das «boas relações».

Alana, por sua vez, mesmo sem conhecer, potencializou o discurso de Luana. Quando questionada sobre possíveis traumas na condução de sua vida no seu terreiro de origem, falou sobre a postura de alguns homossexuais nas comunidades-terreiro. Ela disse que não podia utilizar adornos que coadunam com sua identidade de gênero feminina, mas os membros homossexuais (ou não) de sua comunidade religiosa, que negavam a ela a vivência plena de sua feminilidade, exibiam altos turbantes e outros adornos que poderiam ser lidos como demasiadamente exagerados ou até femininos. Ela era considerada «criativa» por sua Yalorixá por compor figurinos litúrgicos possíveis de serem utilizados nas cerimônias públicas e privadas do terreiro, mas em que medida tal criatividade fez com que Alana se sentisse realizada diante da impossibilidade de vivenciar, no seu espaço religioso, a sua identidade de gênero?

\section{Relações interpessoais}

As relações nas comunidades-terreiro deveriam ser baseadas no respeito mútuo entre os adeptos da religião. Luana, Mauro e Alana tratam sempre de rea-

Sobre esses temas, ler Júlio Braga (1995). 
firmar que suas comunidades foram acolhedoras para com elas/ele, entretanto, diversas situações de violência ocorreram no cotidiano. Agressões verbais, olhares e risos sarcásticos são alguns dos exemplos dessas violências. Vejamos como as pessoas interlocutoras se sentem em relação ao seu convívio religioso nos terreiros.

Eu não tenho o que falar, eu fui uma pessoa assim abençoada e meus irmãos, naquela época que eu fiquei na casa, que hoje eu não frequento, me receberam, me respeitaram, sempre. Nunca me senti excluída, entendeu? Sempre dormia junto com as mulheres, não dormia perto dos meninos. O banheiro eu sempre usava junto com as mulheres. Eu me sentia em casa. (Luana, entrevistada em 17 de maio de 2016)

Segundo Luana, existia uma relação de cordialidade entre os adeptos do terreiro onde ela foi iniciada. Entretanto, poderíamos perguntar: o facto de ela dormir nos dormitórios femininos não seria uma medida protetiva da moral da comunidade-terreiro, uma vez que o dirigente se preocupa com a organização do terreiro bem como com os olhares dispensados sobre sua casa de culto por suas mais velhas? ${ }^{8}$

Mauro, por sua vez, fala dessas relações do lugar de uma autoridade religiosa, afinal foi iniciado na religião com um cargo que lhe coloca na hierarquia da casa, ${ }^{9}$ ao lado do Babalorixá, o que não impediu seus frequentes afastamentos do Axé. Os afastamentos resultaram da intromissão de adeptos da comunidade na vida pessoal dele. No entendimento de Mauro, isso ocorre com todos os adeptos.

Para Alana, a presença das pessoas transexuais cria um impasse nos terreiros.

Enquanto eu me via enquanto ela, eles me viam enquanto ele. Eu era o veadinho que tinha que acordar cedo, que tinha que arrumar o barracão, que tinha que fazer tudo e não era vista como aquela menina delicada que tinha seus momentos de dormir, de acordar. Então, era uma relação difícil e cruel. (Alana, entrevistada em 1 de fevereiro de 2017)

Embora na sua comunidade-religiosa de origem Alana vivesse processos de negação de sua identidade de gênero, em se tratando da comunidade-terreiro Unzo de Ungunzo Kissimbe Amazi, gerida por ela, a relação está em um outro pata-

8 A questão da idade é central para pensar as relações dentro do Candomblé. As pessoas mais velhas são aquelas com mais anos de santo, ou seja, aquelas que foram iniciadas há mais tempo. Mauro foi iniciado no Candomblé como Equéde, um cargo honorífico concedido para mulheres e que possui uma certa posição na hierarquia do Candomblé. Equédes, via de regra, não entram em transe. O mesmo não aconteceu com Alana e Luana, que foram iniciadas como İyàwó (ou iyawô, yao e iâ̂), pessoas que entram em transe para incorporar os Orixás. Iaôs, em geral, só receberão algum cargo no Axé depois de cumprirem as obrigações de sete anos de iniciação. 
mar de respeito às identidades trans e travestis, ainda que ela enfrente alguns percalços, como em toda comunidade-terreiro.

Ela sugere que as pessoas adeptas do Candomblé repensem o modo como têm tratado suas/seus irmãs/irmãos trans. As relações entre adeptos/as (sejam dirigentes ou não) são organizadas a partir da falta de informação/conscientização citadas por Luana e Mauro. Consideramos que pessoas adeptas das religiões de matriz africana (e outros segmentos religiosos) são passíveis de transformação através das micropolíticas de afeto. $\mathrm{O}$ respeito à identidade da outra pessoa é requisito principal para a humanização de espaços como os terreiros de Candomblé.

\section{Divisão no trabalho litúrgico}

Os afazeres nos rituais ${ }^{10}$ são outros momentos cruciais para verificar como as identidades transexuais são tratadas nos terreiros. A divisão do trabalho litúrgico no Candomblé obedece a uma tradição instituída pelas convicções de algumas/ alguns líderes religiosas/os. Para as nossas pessoas interlocutoras, nesses momentos rituais elas são novamente subalternizadas. Para Alana, por exemplo, foram os momentos de divisão de tarefas que a colocaram na condição de «veadinho»e negaram sua feminilidade. Em suas palavras:

Assim, quando eu fui iniciada, eu era aquele garotinho fragilizado que não podia pegar peso, mas podia lavar uma pilha de prato, podia limpar o barracão todo, podia limpar a casa do pai de santo. Estas funções mais pesadas de homens eu não tinha, mas eu era tratada enquanto menino dentro do terreiro por não aceitarem a minha identidade de gênero. A minha identidade de transexual, que sou. Então, eu tinha que vestir batinha quadrada, calça. Não podia usar sapatinho de salto, era chagrim ou babucha. Eu tinha que me comportar como eles queriam e não como eu me aceitava, como me via dentro daquele lugar. Onde eu fui escolhida para nascer. Eu não caí ali de paraquedas nem fui empurrada. Eu caí ali porque o santo ${ }^{11}$ escolheu aquele lugar para nascer, não é? E que os próprios adeptos do Candomblé acabam trazendo isso para dentro da própria religião de matriz africana. Só mulher pode dançar em certos lugares, só mulher não pode fazer certas coisas. É homem que veste azul, é a mulher que veste rosa. É Oxum que veste amarelo, mas é Ogum que veste cinza. Eu acho que

$10 \quad$ O Candomblé possui uma grande variedade de rituais, alguns privados, dos quais só podem participar pessoas iniciadas, e outros públicos, como as festas, realizadas anualmente em homenagem aos orixás ou sempre que alguém é iniciado na religião. Em alguns desses rituais existem coisas que só homens ou mulheres podem fazer.

11 «Cair no santo» ou «bolar» é uma expressão utilizada no Candomblé para se referir ao momento em que uma pessoa que ainda não faz parte daquela casa ou da religião perde os sentidos e cai no chão. Isso significa, para as pessoas do Candomblé, que o Orixá daquela pessoa quer ser cultuado naquela casa de Candomblé. 
o mundo de Orixá é um mundo diverso. Quem disse que Ogum na África veste cinza ou azul? Quem disse que Oxum na África veste rosa ou amarelo? Então, é essa desconstrução que vem tendo dentro da religião. Eu vejo isso muito além. Nesse povo antigo, arcaico, lá da época da escravidão, que foram massacrados, as três princesas que trouxeram o Candomblé aqui para a Bahia. Então, isso vem de culturas dos nossos antepassados que é difícil de quebrar, mas não é difícil de lidar. Se for construído, você consegue adentrar o Ilê Axé Opô Afonjá para falar de mulheres trans. Vai conseguir entrar no Oxumaré, o Cobre, o Gantois. ${ }^{12}$ (Alana, entrevistada em 1 de fevereiro de 2017)

Alana implica a comunidade religiosa a se posicionar sobre as práticas litúrgicas nas comunidades-terreiro. As normas de gênero destinadas a homens e a mulheres são construções sociais que edificam práticas seculares de divisão social (e sexual) do trabalho religioso. Enquanto isso, para alguns dirigentes, tais papéis emanam da energia do Orixá para o qual as pessoas tenham sido iniciadas e não do sexo/gênero da pessoa.

A Nengua Nkisi Alana enfatiza que quando algum homem cisgênero não pode realizar uma função considerada do universo masculino (como a sacralização de determinadas oferendas, encorar atabaques, organizar previamente a casa nos períodos festivo-religiosos), as mulheres assumem tais funções. No entanto, para o Babalorixá de Luana, as atividades litúrgicas às quais ela (ou, ainda, uma mulher cisgênero) estaria apta a realizar são tarefas que passam pelo universo feminino como, por exemplo, bater $i j e,{ }^{13}$ rituais internos para Orixás como Nanã e Obá, que prescindem da presença masculina em todos os seus ritos, dentre outras funções.

O que nos parece é que novas configurações se vão constituindo a partir das necessidades reais das casas de culto e assim a tradição vai perdendo campo para os processos relacionais diante das emergências cotidianas. As/os interlocutoras/es desse estudo são compreendidas/os pelos olhares de seus dirigentes e irmãos/ãs mais velhos/as como corpos que desestabilizam as normas hegemônicas de gênero no contexto sociopolítico das comunidades-terreiro.

E muitas pessoas trans deixam de fazer seu orixá, deixam de cuidar [do seu santo]. De filha de santo, ela passa a ser uma cliente da casa. Porque muitas não querem se envolver por causa desses motivos. Se você for olhar, tem muitas travestis que trabalham. Hoje vivem da vida noturna. É seu trabalho. Tem as transexuais também que têm uma vida normal, comum, que trabalham. E deixam de ser filha para poder ser cliente. $\mathrm{O}$

Refere-se às casas matriz do Candomblé na Bahia.

Esse é um rito específico realizado no momento da divisão do Axé pelos assentamentos dos Orixás que estão recebendo as oferendas nos períodos/momentos de função religiosa. Em determinadas casas em especial, pessoas de Yemonja e Oxum são requisitadas para esse rito. 
certo era ser cliente e passar a ser filha. Mas devido a essas coisas que acontece acaba se afastando, porque você quer ser respeitada lá dentro. Você quer usar uma roupa. Poxa, você tem vontade. Você passa na rua, você vê um tecido bonito que você quer levar para o seu Orixá, ou senão você quer fazer uma roupa para você mesmo, uma saia e você não pode levar. Fica ali naquele padrão. É frustrante isso. Complicado [...]. Sabe o que eu penso? Para eu discutir sexualidade, discutir o que passa na nossa cabeça trans, de homossexual, de bissexual. São coisas que a gente vai se entender porque a gente passa por esse processo. Eu queria ter uma palestra, eu queria estar em um grupo onde outras pessoas estivessem junto para poder eles entenderem o que a gente pensa e aí ouvir a ideia deles também. (Luana, entrevistada em 17 de maio de 2016)

Para Luana, a saída seria a conscientização. Já para Mauro, informação é fundamental.

Mauro é homem e a forma como Mauro se traja é indiferente para o Orixá. Esse bloqueio está na cabeça das pessoas. Nós trans não temos problemas com os Orixás. Se o que vale ali é o que eles acham certo. Se os princípios que valem são os princípios ensinados pelos Orixás, eu percebo a cada dia e a cada local que eu me vejo que os mesmos estão evoluindo junto com a humanidade. Mas a humanidade que os representa não está fazendo questão de evoluir para que nos aceitem de uma forma tranquila e confortável. Porque eles (os Orixás) nos agregam, eles nos aceitam, mas essas pessoas nos bloqueiam. Então, eu acho que esse é o trabalho que tem que ser feito em cada casa que não tivemos acesso. De alguma forma levar essas informações para aqueles Babalorixás, Yalorixás. A existência de pessoas trans dentro do Candomblé, a cada dia, está aumentando. E eles precisam evoluir junto com essas pessoas. Imagina se todo mundo virasse trans? O que seria do Axé? (Mauro, entrevistado em 4 de abril de 2016)

Mauro se reporta ao Orixá como a força que o aceita (a ele e a todas as pessoas indistintamente) e propõe intervenções mais pontuais para que as comunidades religiosas do Candomblé tenham mais informações sobre temas como a transexualidade. Mas o Candomblé deixaria de existir se todas as pessoas fossem trans? Eis a resposta dele:

Não, não deixaria. Porque a pessoa não se define pelo que ela representa. Não dentro. Não o espiritual. Não o emocional. Não o caráter. Isso daqui é só como a gente se sente confortável. É simples. É fácil de aceitar. Basta você botar na sua cabeça. Uma palavra-chave: respeito. Respeite a minha opinião. Respeite a minha vontade. (Mauro, entrevistado em 7 de abril de 2016) 


\section{Conclusões}

Cada filha/o tem suas ligações com seus Orixás. Luana, Mauro e Alana possuem relações de aproximação, amor, respeito, admiração e, sobretudo, obediência aos Orixás que regem as suas vidas. Oxum representa a fértil promessa de uma relação cordial entre Luana com suas lideranças religiosas bem como suas/seus irmãs/irmãos de Axé. Ossain promove a cura pelas folhas que agenciam o bem-estar entre Mauro e suas novas relações em uma casa onde rege o seu Orixá de cabeça. Dandalunda traz a paz das águas doces, mas com a astúcia de uma guerreira que não mede esforços em trilhar batalhas junto com sua filha Alana, que está sempre disposta a um bom debate.

Nos Candomblés de Salvador há uma ambiguidade. De um lado, muitas casas acolhem e enaltecem a presença de pessoas transexuais e travestis quando permitem a presença delas em suas dependências e, de outro, ancoram-se na tradicionalidade, construída na/pela busca de um ideal de "pureza» que as religiosidades afro-brasileiras nunca possuíram em sua totalidade. E, assim, acabam por corroborar com a perpetuação de uma sociedade patriarcal, heteronormativa e cisgênero.

A pequena presença de pessoas transexuais e travestis nos cultos públicos da maioria das casas de Candomblé reflete o projeto silencioso e bem orquestrado de apagamento dessas identidades. Mas isso não quer dizer que em muitas casas elas não se façam presentes. No entanto, muitas vezes elas precisam abdicar de uma parte primordial de suas vidas: a sua identidade de gênero. E assim o acolhimento nunca será completo. As pessoas interlocutoras deste trabalho tendem a pensar que as suas comunidades-terreiro possuem algum diferencial em relação ao grande número de casas de Candomblé para as quais as pessoas transexuais e travestis são apenas motivos para risos sarcásticos, chacotas ou ainda falas que deslegitimem as suas identidades. A invisibilidade é um reflexo do modo como muitas/os dirigentes religiosas/os tratam o tema da transexualidade.

Desse modo, uma estratégia para sair do campo da invisibilidade é galgar o posto hierárquico de maior representatividade no Candomblé, como fez Alana, que vem potencializando a desconstrução do preconceito contra pessoas trans como líder religiosa a partir de micropolíticas em sua casa de Candomblé (e fora dela). Outra possibilidade é um processo de sensibilização de outras lideranças religiosas do Candomblé, no sentido de possibilitar diálogos sobre essas identidades. 


\section{Referências bibliográficas}

Bastide, Roger. 2001. O Candomblé da Bahia: rito nagô. São Paulo: Companhia das Letras.

Bomfim, Patrick Thiago dos Santos. 2009. Discriminação e preconceito: identidade, cotidiano e religiosidade de travestis e transexuais. Dissertação de mestrado - Faculdade de Psicologia, Universidade Católica de Brasília, Brasília. Disponível em: https://bdtd.ucb. br:8443/jspui/bitstream/123456789/1939/1/Texto\%20 completo $\% 20$ Patrick $\% 20$ Thiago\%20Bomfim\%20-\%202009.pdf [Consultado em 21 de dezembro de 2015].

Braga, Júlio. 1995. Na gamela do feitiço: repressão e resistência nos candomblés da Bahia. Salvador: EDUFBA.

Butler, Judith. 2008. Problemas de gênero: feminismo e subversão da identidade. Rio de Janeiro: Civilização Brasileira.

Colling, Leandro, e Gilmaro Nogueira. 2014. «Relacionados, mas diferentes: sobre os conceitos de homofobia, heterossexualidade compulsória e heteronormatividade». In Transposições: lugares e fronteiras em sexualidade e educação, organizado por Alexsandro Rodrigues, Catarina Dallapicula, e Sérgio Rodrigo da S. Ferreira, 171-184 Vitória: EDUFES.

Dantas, Beatriz Góis. 1988. Vovó Nagô, Papai Branco: usos e abusos da África no Brasil. Rio de Janeiro: Graal.

Goikoetxea, Itziar Gandarias, e Nagore García Fernández. 2014. «Producciones narrativas: una propuesta metodológica para la investigación feminista». In Otras formas de (re) conocer: reflexiones, herramientas y aplicacionais desde la investigación feminista, organizado por Irantzu Mendia Azkue et al., 97-110. Bilbao: Universidad del País Vasco.

Jesus, Fátima Weiss. 2012. Unindo a cruz e o arco-íris: vivência religiosa, homossexualidade e trânsitos de gênero na Igreja da Comunidade Metropolitana de São Paulo. Tese de doutorado - Centro de Filosofia e Ciências Humanas, Universidade Federal de Santa Catarina, Florianópolis. Disponível em: http://nigs.ufsc.br/files/2012/01/TESE-FATIMA-WEISS-FINAL.pdf [Consultado em 21 de dezembro de 2015].

Laville, Christian, e Jean Dionne. 1999. A construção do saber - manual de metodologia da pesquisa em ciências humanas. Belo Horizonte: Editora UFMG.

Ribeiro, Luiz Alberto Faria. 2009. Deus é para todos? Travestis, inclusão social e religião. Dissertação de mestrado - Centro de Ciências Sociais, Pontifícia Universidade Católica do Rio de Janeiro, Rio de Janeiro. Disponível em: https://www.maxwell.vrac.puc-rio. br/15055/15055_1.PDF [Consultado em 21 de dezembro de 2015].

Romba, Rui Martins. 2015. O Candomblé no Terreiro de Pilão Branco em São Paulo: estudo de caso sobre o impacto da religião no quotidiano de praticantes pessoas trans. Dissertação de mestrado - Universidade Aberta do Brasil. Disponível em: http://hdl.handle.net/10400.2/ 4463 [Consultado em 21 de dezembro de 2015].

Santos, Ailton da Silva. 2013. «O gênero na berlinda: reflexões sobre a presença de travestis e mulheres transexuais nos terreiros de Candomblé». Comunicação apresentada no III Seminário Internacional Enlaçando Sexualidades, Salvador. Disponível em: http://www. uneb.br/enlacandosexualidades/2013/06/13/1735 [Consultado em 21 de dezembro de 2015].

Vergueiro, Viviane. 2014. «Trans*Sexualidade: reflexões sobre a mercantilização do sexo desde a perspectiva transgênera». Periódicus 1(1): 174-190. Disponível em: https://portal seer.ufba.br/index.php/revistaperiodicus/article/view/10154 [Consultado em 20 de dezembro de 2015].

Vergueiro, Viviane. 2015. Por inflexões decoloniais de corpos e identidades de gênero inconformes: uma análise autoetnográfica da cisgeneridade como normatividade. Dissertação de mestrado 
- Instituto de Humanidades, Artes e Ciências Professor Milton Santos, Universidade Federal da Bahia, Salvador. Disponível em: https://repositorio.ufba.br/ri/handle/ri/ 19685 [Consultado em 10 de dezembro de 2016].

Vuola, Elina. 2015. «Questões teóricas e metodológicas sobre gênero, feminismo e religião». In Gênero, feminismo e religião: sobre um campo em constituição, organizado por Maria José Rosado, 39-57. Rio de Janeiro: Garamond.

Claudenilson Dias. Bacharel em Humanidades (Instituto de Humanidades, Artes e Ciências Professor Milton Santos/Universidade Federal da Bahia - IHAC/UFBA). Mestre e Doutorando pelo PPGNEIM, Departamento de Gênero e Feminismo da Universidade Federal da Bahia. Pesquisador permanente do Núcleo de Estudos sobre Gênero, Cultura e Sexualidade - NUCUS (IHAC/CULT/UFBA).

Correio eletrónico: diasghp@gmail.com

Leandro Colling. Professor Associado I do Instituto de Humanidades, Artes e Ciências Professor Milton Santos/Universidade Federal da Bahia - IHAC/UFBA. Coordenador do NUCUS e autor de livros como Stonewall $40+$ o que no Brasil? (2011); Estudos e politicas do CUS: Grupo de Pesquisa Cultura e Sexualidade (2013) e Que os outros sejam o normal: tensões entre movimento LGBT e ativismo queer (2015).

Correio eletrónico: leandro.colling@gmail.com

Artigo recebido a 25 de junho de 2018 e aceite para publicação a 9 de agosto de 2018. 